\title{
A study on ways to extend public data for game ratings from Korea
}

\author{
HoSeong Kang1 , JungYoon Kim²,*
}

1 Department of Game Engineering, Graduate School, Gachon University, Seongnam-si, 13120, Gyeonggi-do, Republic of Korea; sos6884@naver.com

2 Department of Game Media, College of Future Industry, Gachon University, Seongnam-si, 13120, Gyeonggi-do, Republic of Korea; kjyoon@gachon.ac.kr

* Correspondence: kjyoon@gachon.ac.kr; Tel.: +82-31-750-8666

\begin{abstract}
As of 2020, public data for game ratings provided by Game Ratings And Administration Committee(GRAC) are more limited than public data for movie and video ratings provided by Korea Media Ratings Board and do not provide data which allow us to see information on ratings clearly and in detail. To get information on game ratings, we need to find information by searching for specific target on homepage which is inconvenient for us. In order to improve such inconvenience and extend scope of provision in public data, the author of this paper intends to study public data API which has been extended based on information on video ratings. To draw items to be extended, this study analyzes data for ratings on homepage of GRAC and designs collection system to build database. This study intends to implement system that provides data collected based on extended public data items in a form which users want. This study is expected to provide information on ratings to GRAC which will strengthen fairness and satisfy game users and people's rights to know and contribute to promotion and development of game industry.
\end{abstract}

Keywords: Game Ratings; Public Data; Game Data; Data analysis; GRAC(Korea)

\section{Introduction}

As people's leisure activity and cultural activity have increased, game is growing as people's central cultural activity[1]. In addition, technology has developed, smartphones are becoming more common in people and games which people enjoyed via PC and video game machine have been transplanted to smartphones with high specification which makes it possible for people to enjoy games anytime anywhere. As the demand for game has increased, game industry has grown. According to white paper on game in Korea for 2019 published by Korea Creative Content Agency, as shown in [Figure 1], game industry has shown high growth rate since 2009[2].

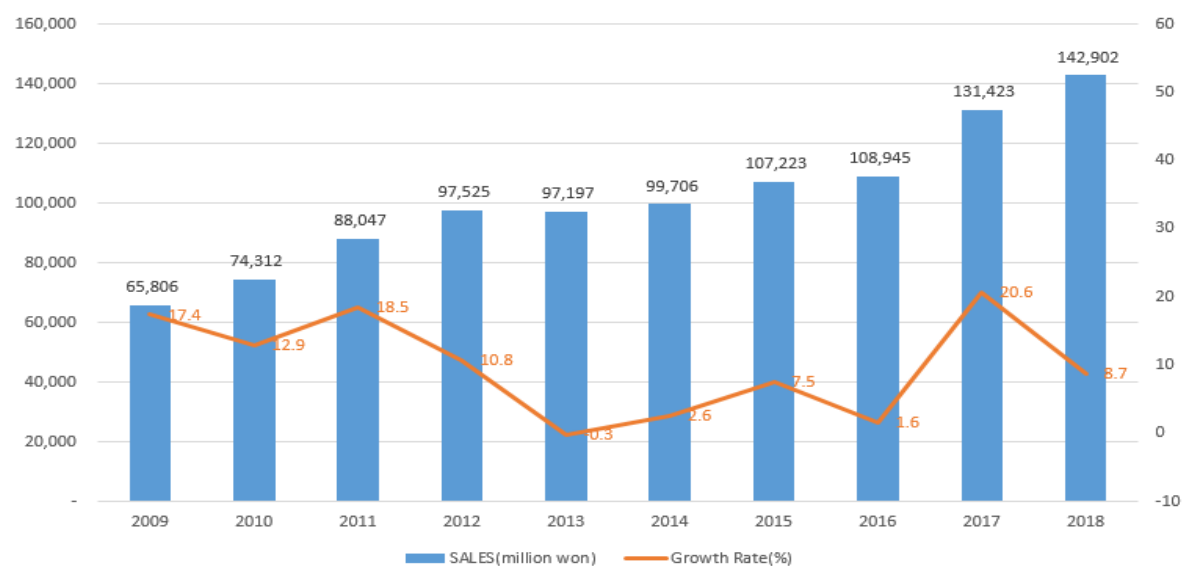

Figure 1. Overall size and growth rate of the Korean game market (2009 2018)[2] 
Korean game market has continued to grow and it has higher amount of export than other markets. At the time that people's interest in game increases and Korean game industry accomplishes good result at home and abroad, regulatory review procedures impedes growth of game industry. According to Article 21 of Game Industry Promotion Act, A person who intends to produce or distribute a game product for the purpose of circulating the game product or providing for the use thereof shall receive a rating for the contents of the game product from the Committee or business entities designated before producing or distributing such game product[3]. Rating review aims to enhance protection of young people and game ethic and prevent speculation but studies and public opinions have reported that rating review is excessively regulative[4-6]. Due to "The Sea Story", speculative game related that occurred in Korea in 2006, Game Ratings And Administration Committee(GRAC) was launched[7]. Rigid and unreasonable review such as indie game regulation on zuzunza.com in 2019[8] and steam regulation in 2020 impeded growth of Korean game industry[9].

Voluntary ratings were implemented to relieve regulation of review and game monitoring unit for ratings was launched in 2019 but as shown in [Figure 1], above mentioned monitoring unit was composed of people who had poor understanding of games such as job discontinued women and people with handicap which led to controversy on fairness and members of expertise[10-12].

Table 1. Controversy over Korea's game monitoring team and qualification requirements for 2019 game monitoring team[10-12]

\begin{tabular}{ll}
\hline \multicolumn{1}{c}{ Conditions of employment qualification } \\
\hline - \\
- Sisabled Person / Career Discontinued Women \\
- People who can participate in monthly offline monthly meetings (required) \\
- the four major uninsured persons \\
\hline
\end{tabular}

It is necessary to study whether GRAC that is responsible for rating and reviewing games discloses information properly and whether rating and reviewing games are performed fairly.

GRAC belongs to public institution and information on game ratings and review is included in public data. Public data aims at "improving life of quality and national economy by promoting people's use of data owned and managed by public institution." which incurs obligation to disclose data on game ratings and review[13]. This study intends to analyze and classify content of public data provided by GRAC and ways to provide public data API information.

In addition, this study intends to provide information on ratings and review to game users and workers in industries so that they can use it.

\section{Analysis of public data by Game Ratings And Administration Committee}

GRAC provides information on games in a form of Open API(Application Programming Interface) according to public data policy.

However information on game rating review which can be obtained through is limited. Contents in [Table 3] are variables and description of information on game rating review that can be received through GRAC API. Data can be obtained as shown in [Figure 2] and [Table 3][14].

Table 2. GRAC OpenAPI - List of Game API Output Variables[14]

Request variable Content




\begin{tabular}{cl}
\hline result & No special meaning as root element of search result \\
tcount & Number of search results \\
res_date & Date and time of search result generation \\
pageno & Search page number \\
item & Game individual search result root element includes below el- \\
ement below. \\
gametitle & Game name \\
orgname & Rating organization \\
entname & Applicant (company) name \\
hoperate & Application rating(All, 12+,15+, 18+) \\
givenrate & Decision rating(All, 12+,15+, 18+, reject(scheduled), reject, can- \\
cellation(scheduled), cancellation) \\
rateno & Rating Classification Number \\
rateddate & Rating classification date \\
\hline
\end{tabular}

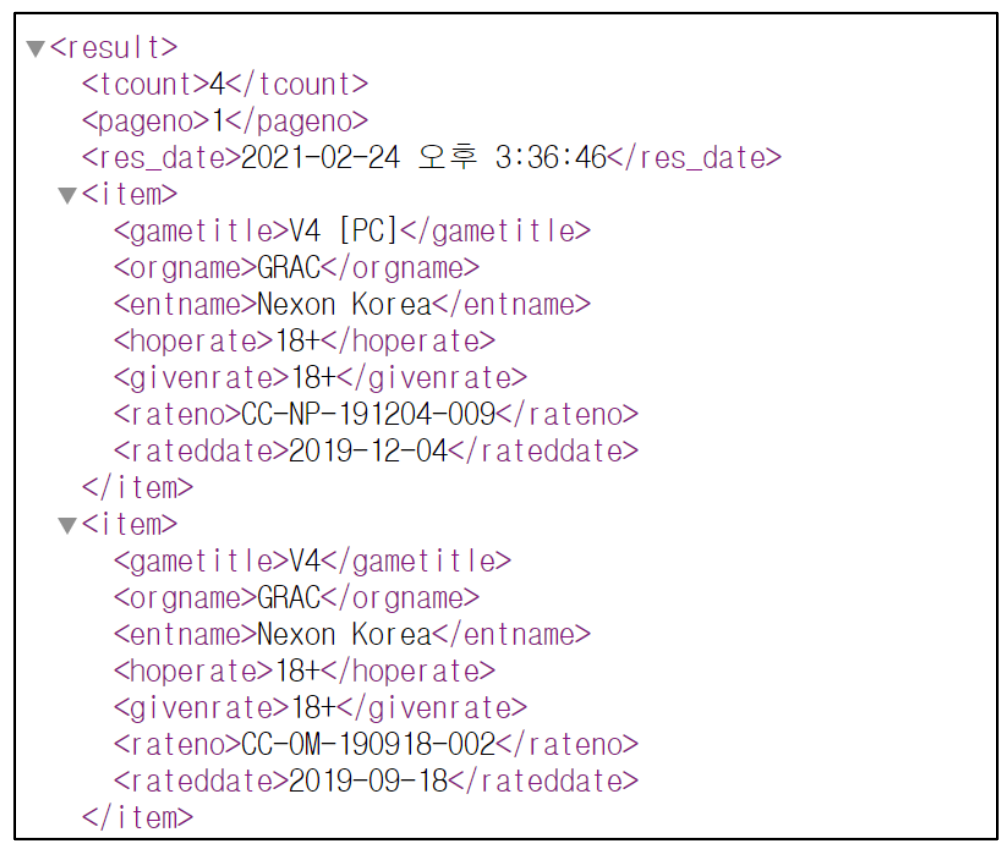

Figure 2. GRAC OpenAPI - Game API Output Result

Table 3. GRAC Contents of providing public data (Game API) [14]

\begin{tabular}{cc}
\hline Item Name & Sample Data \\
\hline Game name & V4 [PC] \\
Rating organization & GRAC \\
Applicant name & Nexon Korea \\
Application rating & $18+$ \\
Decision rating & $18+$ \\
Rating classification number & CC-NP-191204-00 \\
Rating classification date & $2019-12-04$ \\
\hline
\end{tabular}

Data obtained through API as shown in [Figure 2] and [Table 3] simply enumerate results of game ratings and content of information on game and reasons for which specific games received relevant rating is insufficient and limited. On the other hand shown in [Figure 4] Open API which is movie rating provided by Korea Media Rating Board 
includes results of ratings as well as information on movie such as synopsis and lead role and provides reasons for ratings which allows people to check the reasons[15].

Public data that allow people to check information in more detail can be used to satisfy people's rights to know and can be used for application service aiming at providing information on movies.

Table 4. Korea Media Rating Board OpenAPI - Media Rating List API Output Result

\begin{tabular}{cc}
\hline Item Name & Sample Data \\
\hline Director & Jang Joon Hwan \\
Director nationality & Korea \\
Decision rating & $15+$ \\
Leading role & Kim Yoon-seok, Ha Jung-woo, Yoo Hae-jin, Kim \\
Movie species & Tae-ri, Park Hee-soon, Lee Hee-jun \\
Original title & a film drama \\
Production year & 1987 \\
Producer & 2017 \\
Country of production & Friendship film Co., Ltd. \\
Screening time & Korea \\
Standard & 130 minutes 0 seconds \\
Title & 1987 \\
Reasons for core harm & violence \\
Topic & $15+$ \\
Sexuality & All \\
Violence & $15+$ \\
Fear & $15+$ \\
Drugs & $15+$ \\
Lang & $12+$ \\
Imitative risk & $15+$ \\
& Park Jong-chul and the death of Lee Han-yeol's \\
Plot & tear gas. \\
& $2017-$ MF02149 \\
Rating classification number & 20171211 \\
Rating classification date &
\end{tabular}

GRAC needs to provide data and information that conforms to intent of ratings and purpose of public data like Open API which is movie rating. People can check information on games and reviews by browsing it with game name and rating number through rating decision check page on homepage of GRAC.

However, this is not included in public data API and utilization is low because process is complex to get detailed review information on games and data are not provided in a form which can be processed. According to this study intends to collect and analyze data subject to rating review provided by GRAC to enhance utilization and quality of public data.

\section{A study on extension of public data by Game Ratings And Administration Com- mittee}

\subsection{Method of study}

As method of study, based on public data for video rating provided by Korea Media Rating Board as shown in [Figure 3], data for game rating provided on homepage of GRAC is analyzed and items to be improved in public data for game rating are drawn. 
System which allows us to collect data for data rating in a systemical way is designed and implemented and collection and classification are made and database is built to provide users with extended public data.

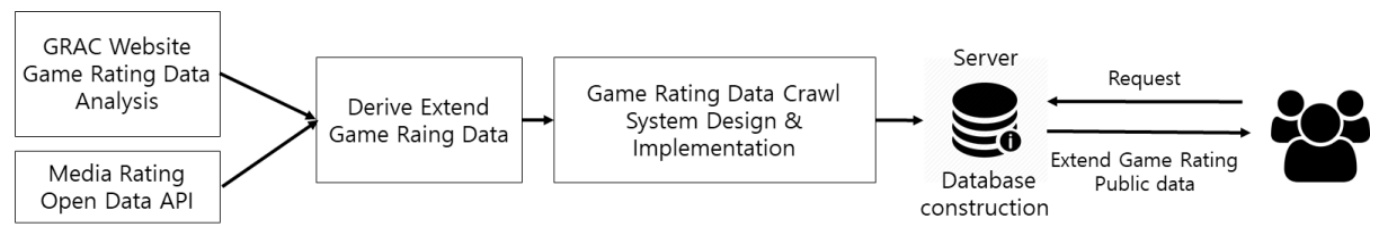

Figure 3. A Study on the Public Data Expansion Model of GRAC

\subsection{Analysis of data for rating by Game Ratings And Administration Committee}

GRAC provides data for game rating which are distributed in Korea via homepage of GRAC[16]. People can check information on games which has been reviewed for rating by GRAC or Game Content Rating Board on page of "check for decision on rating". Page of check for decision on rating allows us to check content of decision on rating of games which review of rating has completed briefly as shown in [Figure 4][16]. There are links that allow us to move to pages which are related to games and rating review such as "page of detailed information on games", "page of a written decision", "page of rating history", and "present condition of acquisition of overseas grade"

\begin{tabular}{|c|c|c|c|c|c|c|c|c|c|c|}
\hline Game title & applicant & $\begin{array}{l}\text { Classification } \\
\text { Date rank }\end{array}$ & $\begin{array}{c}\text { Classification } \\
\text { number }\end{array}$ & cancel & $\begin{array}{c}\text { Decision } \\
\text { date }\end{array}$ & manual & Agency & $\begin{array}{l}\text { decision } \\
\text { Contents }\end{array}$ & $\begin{array}{c}\text { rank } \\
\text { Record }\end{array}$ & $\begin{array}{l}\text { Overseas } \\
\text { rank }\end{array}$ \\
\hline$\underline{V 4}(\mathrm{~V} 4)[\mathrm{PC}]$ & $\begin{array}{c}\text { Nexon Korea Co., Lt } \\
\text { d. }\end{array}$ & $\begin{array}{l}2019- \\
12-04\end{array}$ & $\begin{array}{l}\text { CC-NP-191204- } \\
009\end{array}$ & & $\begin{array}{l}2019- \\
12-04\end{array}$ & & 7 & 렬정 & 미력 & \\
\hline V4 (V4). & $\begin{array}{c}\text { Nexon Korea Co., Lt } \\
\text { d. }\end{array}$ & $\begin{array}{l}2019- \\
09-18\end{array}$ & $\begin{array}{l}\text { CC-OM-190918 } \\
-002\end{array}$ & & $\begin{array}{l}2019- \\
09-18\end{array}$ & & 7 & 졀정 & 미력 & \\
\hline
\end{tabular}

Figure 4. Check for decision on rating Page (Google Translate Web)

Page of detailed information on games allow us to check detailed information on games which requested rating as shown in [Figure 5]. People can move to relevant page via hyperlink of game name on page of check for decision on rating. [Table 5] shows items that people can check. Each item includes basic information on games such as "genre" and "nationality" and people can check basic information on rating for example "date of rating" and "rating number", [Table 5] is summary of description and sample data according to items on relevant page. 


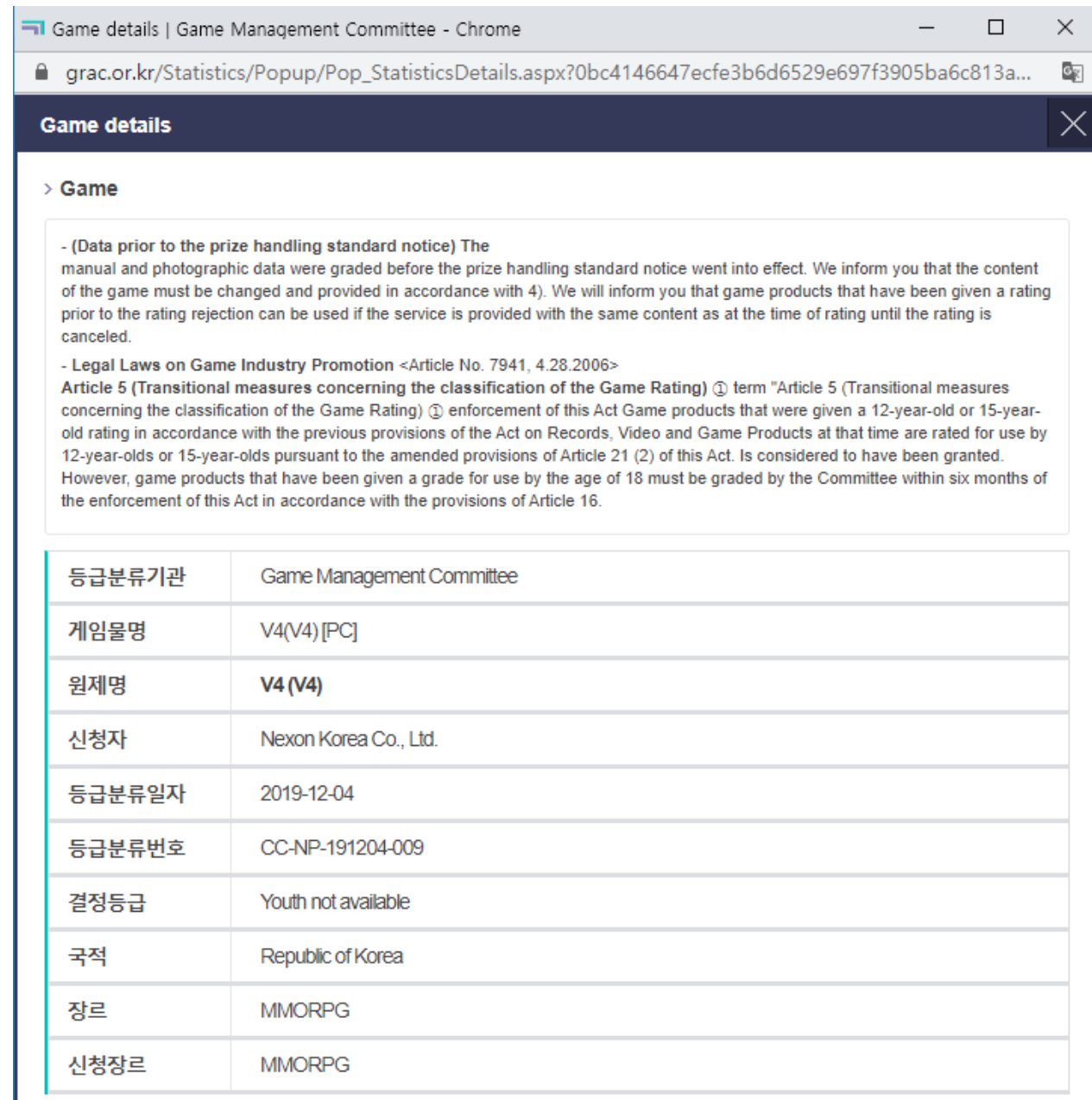

Figure 5. Game Details (Google Translate Web)

Table 5. Game Details Item Description

\begin{tabular}{cc}
\hline Item & Sample data \\
\hline Rating organization & GRAC \\
Game title & V4 [PC] \\
Original Game Title & V4 \\
Applicant name & Nexon Korea \\
Rating classification date & $2019-12-04$ \\
Rating classification number & CC-NP-191204-009 \\
Decision rating & $18+$ \\
Country & Korea \\
Genre & MMORPG \\
application genre & MMORPG
\end{tabular}

Page of a written decision on game rating allows people to check a decision on rating of games which requested rating review as shown in [Figure 6]. Content of decision on games that requested rating includes reason for rating, description of game in one sentence and information on game contents. In item of "indication of content information", sensationality, violence, fear, unsuitability of languages, drug, crime, and speculation are indicated based on standard for consideration of rating in relevant studies. 
People can collect data for indication of content information which influences rating and reason for decision on game rating on page of a written decision on games. [Table 6] is summary of description and sample data according to items on relevant page.

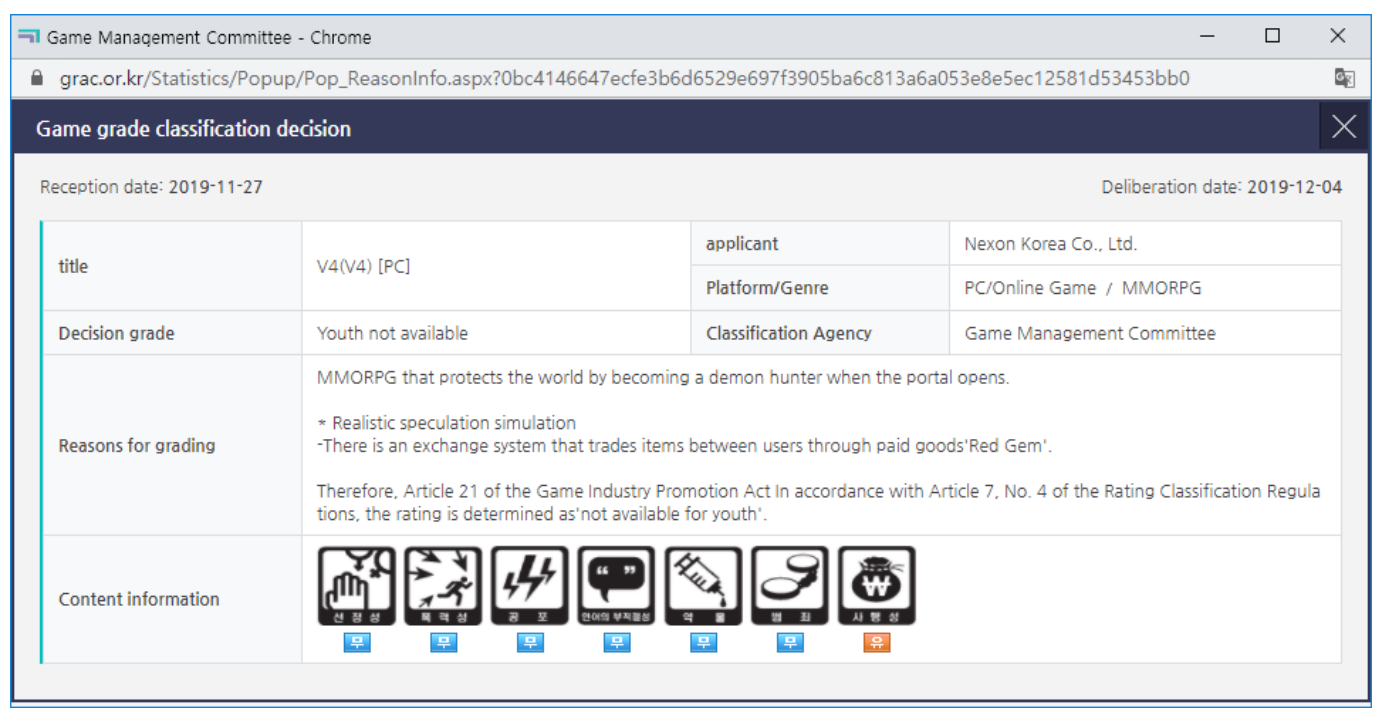

Figure 6. Game rating on page of a written decision on games Page(Google Translate Web)

Table 6. Game rating on page of a written decision on games Item Description

\begin{tabular}{cc}
\hline Item & Sample data \\
\hline Game title & V4 [PC] \\
Applicant name & Nexon Korea \\
Platform/Genre & PC/OnlineGame/MMORPG \\
Decision rating & $18^{+}$ \\
Rating organization & GRAC
\end{tabular}

Reasons for rating

When the portal opened, MMORPG became a demon hunter and protected the world.

* Copying realistic gambling practices

- Exchange system exists to trade items between users through paid goods 'Red Gem' (skip)

Content Descriptors (sexuality, violence, fear, language, drugs, crime, gambling)

YES: gambling

NO: sexuality, violence, fear, language, drugs, crime

[Table 7] proposes items to be improved by drawing items needed from "page of detailed information on games" and "page of a written decision on game rating" and setting two items of game information and rating review information based on public data provided by Korea Media Rating Board. Relevant items can be extracted from database of GRAC that has information on games and can be collected from page of GRAC. Using sample data allows us to check information on game rating review more clearly and prepare foundation that can be used in analyzing and visualizing big data. 
Table 7. Game Rating Classification Information Public Data Extension Item Description and Sample Data

\begin{tabular}{cc}
\hline Item & Sample data \\
\hline Game title & V4 [PC] \\
Country & Korea \\
Decision rating & $18+$ \\
hoperate & $18+$ \\
Rating organization & GRAC \\
Applicant name & Nexon Korea \\
Genre & MMORPG \\
Platform & PC/OnlineGame \\
& - Exchange system exists to trade items between \\
Reasons for rating & users through paid goods 'Red Gem') \\
& NO \\
sexuality & NO \\
violence & NO \\
fear & NO \\
drug & NO \\
language & NO \\
crime & YES \\
gambling & When the portal opened, MMORPG became a \\
Rating classification number & demon hunter and protected the world. \\
Rating classification date & CC19-12-04 \\
\hline
\end{tabular}

\subsection{Designing and implementing public data collection system for extending game rating}

As shown in [Table 7], this study intends to design system which collects game rating data to provide extended game rating public data to users. As shown in [Table 8], collection system was designed and built based on system environment. Parsing technique which is easy to specific data or items was used and Jsoup library aiming at parsing in Java environment was used. Jsoup is library which is easy to find or extract data that users want by using DOM search or CSS selector and can implement process of collection by accessing page with simple code. Jsoup allows people to make analysis and access ineffective tag and proven tag and provides trees structure type approach[17].

Table 8. Data Collection System Environment

\begin{tabular}{cc}
\hline Item & Contents \\
\hline Base language & JAVA \\
Development environment (program) & Eclipse \\
Development environment (OS) & Windows 10 64bit \\
Development equipment & I7-7700K 4.20GHz, RAM 16GB \\
Using library & Jsoup \\
\hline
\end{tabular}

System was designed as shown in [Figure 7] to collect rating data from homepage of GRAC. System consists of URL collection module, connection module, detailed collection module, and storage module. Scheduler controls requests and modules. 


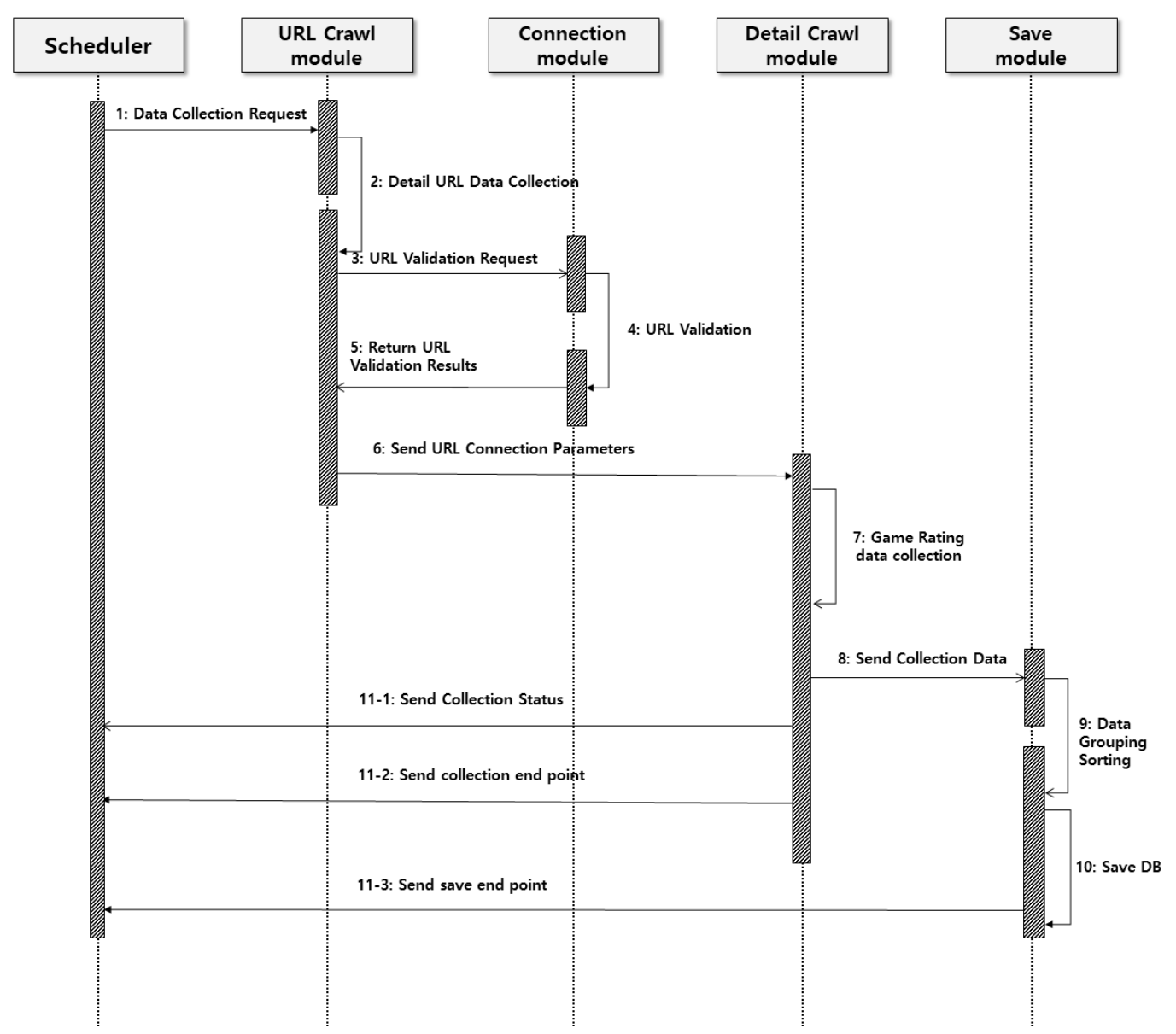

Figure 7. Classification Data Acquisition System Sequence Diagram

System collects detailed page URL of each game and then verifies whether data exists in relevant URL. Then access detailed page URL of each game and collect data for rating and store it on database and build data for game rating. Deliver state of whether data are stored normally by scheduler and time on which collection is finished and time on which storage is completed. Data for game rating were collected by implementing system and a total of 80180 data were collected from May 12, 2020 to May 15, 2020.

Table 9. Data Collection History

\begin{tabular}{cc}
\hline Item & Contents \\
\hline Data Range Collected & $1988 \sim 2020.05 .10$ \\
Registered Games & 80,180 \\
Game Details Page & 80,180 (Contains pages where only URLs exist) \\
Classification Decision Page & 29,963 \\
\hline
\end{tabular}

If a user requests information on game on game rating database built through collection system, pre-indexed data set delivers requested data. Arrange requested data sequentially based on ID and then provide it to users in a form of XML and JSON as shown in [Figure 8]. 


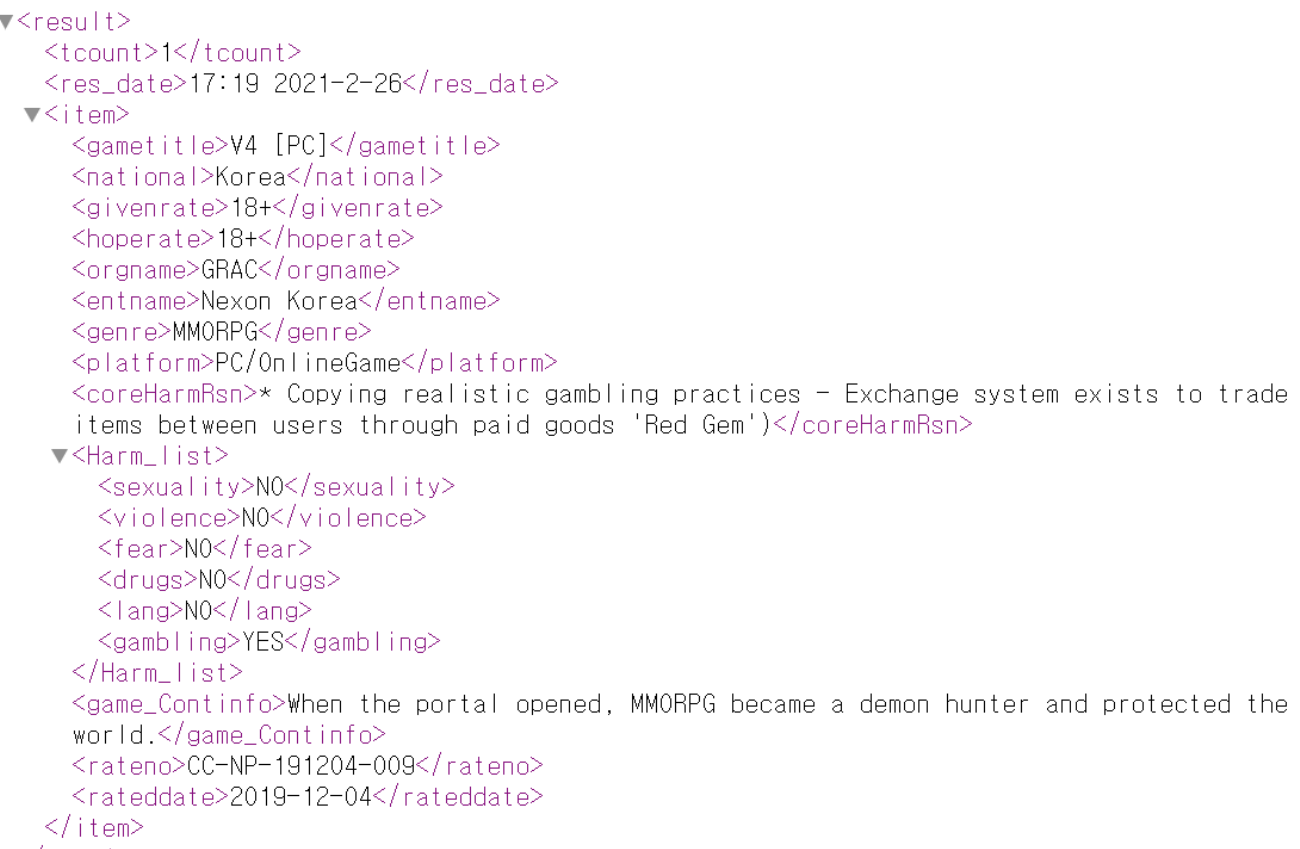

(a) $\mathrm{XML}$

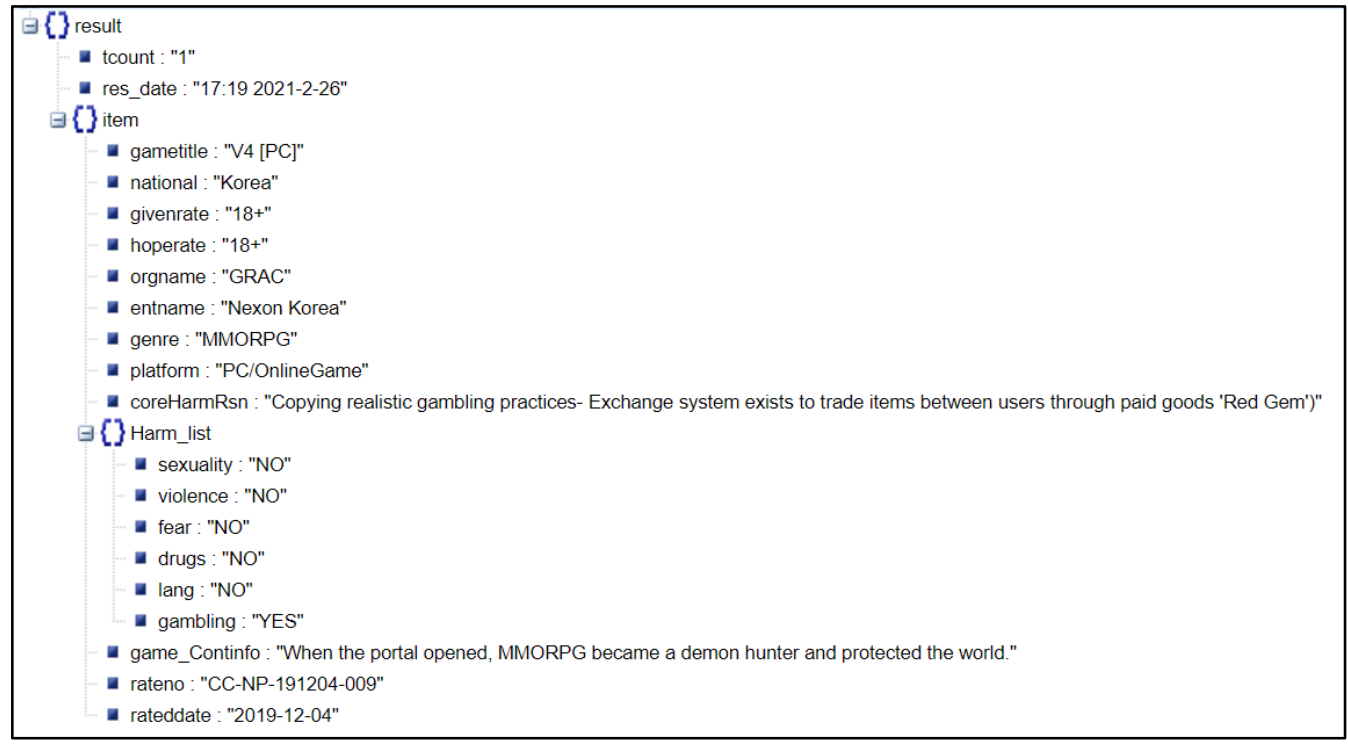

\section{(b) JSON}

Figure 8. Classification Extended Public Data Output Results(ENG) (a) XML, (b) JSON

[Table 10] shows API result data and extension result data provided by GRAC. Existing data show fragmentary one such as game name, decided rate and rating institution. On the other hand, extended data show detailed information on games genre, platform, and description of games and reasons for review, sensationality, violence. Extended data can be used as basic data in analyzing rating. 


\begin{tabular}{ccc}
\hline Variable Name & Existing API Results Data & Extended Results Data \\
\hline gametitle & V4 [PC] & V4 [PC] \\
national & - & Korea \\
givenrate & $18+$ & $18+$ \\
hoperate & $18+$ & $18+$ \\
orgname & GRAC & GRAC \\
entname & Nexon Korea & Nexon Korea \\
Platform & & PC/OnlineGame \\
genre & - & MMORPG \\
& & *opying realistic gambling practices \\
coreHarmRsn & - & - Exchange system exists to trade \\
& & items between users through paid \\
sexuality & - & goods 'Red Gem') \\
violence & - & NO \\
fear & - & NO \\
drugs & - & NO \\
lang & - & NO \\
crime & - & NO \\
gambling & - & NO \\
game_Continfo & CC-NP-191204-009 & YES \\
rateno & $2019-12-04$ & When the portal opened, MMORPG \\
rateddate & & CC-NP-191204-009 \\
\hline
\end{tabular}

\section{Conclusion}

It is necessary to examine whether GRAC provides information on game rating review properly and fairly in terms of game users and game industry. Studies show that GRAC has played a role as public institution and its rating review has impeded game industry. Most papers cover validity of information on rating review in terms of sociology and law and few papers cover validity of information on rating review in terms of engineering. This study analyzed types and contents of data for game rating review provided by GRAC and designed data collection system and collected relevant data to obtain extended public data. Analysis showed that data for game rating review were dispersed. This study made a plan for collection to collect dispersed data and designed and implemented structured system. A total of 80180 data were collected and foundation for providing extended public data was built.

The author of this study intends to conduct a study on advanced big data analysis such as prediction of time that takes to review games, overseas rating and comparative analysis by using fourth industrial revolution's ICT for example machine learning and artificial intelligence based on experiment and collected data by extending big data analysis method such as grouping and factor analysis.

Author Contributions: Conceptualization, K.-H.S.; Data analysis, K.-H.S.; data curation, K.-H.S.; writing-original draft preparation, K.-H.S. and K.-J.Y.; writing-review and editing, K.-J.Y.; All authors have read and agreed to the published version of the manuscript.

Funding: This research is supported by Ministry of Culture, Sports and Tourism and Korea Creative Content Agency(Project Number: R2020040243). 
Institutional Review Board Statement: Not applicable.

Informed Consent Statement: Not applicable.

Data Availability Statement: The data presented in this study are available on request from the corresponding author.

Acknowledgments: This research is supported by Ministry of Culture, Sports and Tourism and Korea Creative Con-tent Agency(Project Number: R2020040243), This work was supported by the Gachon University research fund of 2020(GCU-202008460010), Excerpt submitted thesis by HoSeong, Kang for Master's degree, University of Gachon, South Korea, 2020.

Conflicts of Interest: The authors declare no conflict of interest.

\section{References}

1. Yang, J.M. Emerging Power in the Cultural Industries: U.S.- China Competition in Video Game Industry. RIAS 2020, 29, 121-150.

2. 2019 White Paper on Korean Games (KOCCA). Available online: https://www.kocca.kr/cop/bbs/view/B0000146/1841389.do (accessed on 7 March 2021).

3. Act on the Promotion of the Game Industry Promotion Act(Korea). Available online: https://www.law.go.kr/\%EB\%B2\%95\%EB\%A0\%B9/\%EA\%B2\%8C\%EC\%9E\%84\%EC\%82\%B0\%EC\%97\%85\%EC\%A7\%84\%ED \%9D\%A5\%EC\%97\%90\%20\%EA\%B4\%80\%ED\%95\%9C\%20\%EB\%B2\%95\%EB\%A5\%A0/\%EC\%A0\%9C21\%EC\%A1\%B0 (accessed on 7 March 2021).

4. Kim, J.I. Problems of Game Rating Policy in Korea and Proposal for Improvement. HUFS. Law. Review. 2017, 41, 89-117. Doi: 10.17257/hufslr.2017.41.4.89

5. Hwang, S.G. The Present State and Improvement Direction of the Major Regulations on Internet Game. JML. Ethics and Policy. 2018, 17, 1-35. Doi : 10.26542/JML.2018.12.17.3.1

6. Lee, S.H. Case Study on Rating Practice of GRAC that Restrict Freedom of Expression. KSCG 2015, 28, 75-82. Doi : 10.22819/kscg.2015.28.4.010

7. Kim, C.S.; Park, T.S. Consideration on Role and Functions of Game Rating Board. Jour. of KoCon.a 2007, 7, 114-122.

8. Kim, S.W.; Jung, H.S.; Lee, H.S. A Study on Improvement Way of Game Rating System. JKGS 2019, 19, 15-37. Doi :10.7583/JKGS.2019.19.5.15

9. Controversy over 'steam regulation'...Behind the scenes of "illegal distribution. Available online: https://www.etnews.com/20200608000216 (accessed on 7 March 2021).

10. About career interrupted women, disabled people, and professionalism of the monitoring team of the Game Committee. Available online: https://www.gamemeca.com/view.php?gid=1459016 (accessed on 7 March 2021).

11. The eyes on the game are 'housewives'... Monitoring bias severe. Available online: http://www.topdaily.kr/news/articleView.html?idxno=51284 (accessed on 7 March 2021).

12. GRAC 'game monitoring team'... "Professionalism" concerns still remain. Available online: http://biz.newdaily.co.kr/site/data/html/2019/04/09/2019040900155.html (accessed on 7 March 2021).

13. The Act on the Promotion of Public Data Provision and Utilization(Korea). Available online: https://www.law.go.kr/\%EB\%B2\%95\%EB\%A0\%B9/\%EA\%B3\%B5\%EA\%B3\%B5\%EB\%8D\%B0\%EC\%9D\%B4\%ED\%84\%B0\%EC \%9D\%98\%EC\%A0\%9C\%EA\%B3\%B5\%EB\%B0\%8F\%EC\%9D\%B4\%EC\%9A\%A9\%ED\%99\%9C\%EC\%84\%B1\%ED\%99\%94\%EC $\% 97 \% 90 \%$ EA $\%$ B4\%80\%ED\%95\%9C\%EB\%B2\%95\%EB\%A5\%A0 (accessed on 7 March 2021).

14. Game Ratings And Administration Committee - Game API. Available online: https://www.grac.or.kr/Game3.0/OpenAPIGuide.aspx (accessed on 7 March 2021).

15. Video Rating Board Movie Classification List. Available online: https://www.data.go.kr/data/3043382/openapi.do (accessed on 7 March 2021).

16. Game Ratings And Administration Committee - Check for decision on rating. Available online: https://www.grac.or.kr/Statistics/GameStatistics.aspx (accessed on 7 March 2021).

17. jsoup: Java HTML Parser. Available online: https://jsoup.org/ (accessed on 7 March 2021). 